\title{
aniki
}

Revista Portuguesa da Imagem em Movimento

Portuguese Journal of the Moving Image

\section{A inserção da Globo Filmes no cenário cinematográfico brasileiro} Guibson Dantas ${ }^{1}$, Gárdia Rodrigues ${ }^{2}$

\section{Introdução}

Instituições, manifestações e movimentos sócio-culturais; disputas, interesses e jogos de poder; relações com o Estado, tomadas de posição e formações discursivas, são algumas nuances que atravessam o campo cultural, enquanto importante espaço de produção material e simbólica (Bourdieu 1992). Nessa esteira, temse como propósito, no presente artigo, direcionar o olhar para a inserção da Globo Filmes no cenário cinematográfico brasileiro. Para tanto, o estudo abrange a contextualização das transformações econômicas desse contexto, com ênfase na criação da empresa em apreço, e nos anos subsequentes a tal evento (1998-2007). Apreender os contornos do cinema brasileiro, consideradas aqui as relações com a televisão, são os fios condutores deste texto.

Em um primeiro momento, é possível dizer que a conformação de um cinema nacional, inscrito no próprio processo de modernização da sociedade brasileira (Ortiz 1994), revelou o divórcio estético-político entre cinema e televisão. O trânsito do Estado pelo cinema, com a criação de órgãos e instituições ou, em outros termos, a condição de instituição nacional atribuída ao cinema (Miceli 1984); a comunicação enquanto fator de integração da sociedade (Mattelart 2005); e a tentativa de construção de uma indústria cinematográfica brasileira através da formação de companhias nacionais (Cinédia, Atlântida e Vera Cruz), foram outros demarcadores desse período.

Outra alternativa de modernização, repousada em uma ideologia nacional-popular, assinalou os anos seguintes. A nova postura reportava a uma estrutura de sentimento de brasilidade romântico-revolucionária (Ridenti 2000), construída e compartilhada pelos meios artísticos e culturais desde meados dos anos 1940, e pronunciada a partir dos anos 1960. Nesse sentido, houve uma imbricação entre os processos estético-cultural e político-social, e um rompimento com os referenciais fílmicos estrangeiros. As propostas do Cinema Novo foram orientadas pelo nacionalismo, pela

\footnotetext{
${ }^{1}$ Universidade Federal de Alagoas, Instituto de Ciências Humanas, Comunicação e Artes,57072-900 , Maceió, Brasil.

${ }^{2}$ Universidade Federal Fluminense, Faculdade de Direito, 24210-510, Niterói, Brasil.
} 
vertente nacionalista|culturalista, em contraposição à vertente universalista|industrialista (Ortiz Ramos 1983).

O processo ditatorial e a modernização conservadora conferiram outros contornos ao cinema nacional. Cabe mencionar a instituição da Empresa Brasileira de Filmes S/A (EMBRAFILME), e as distintas fases da agência, delineadas por articulações políticas, econômicas e cinematográficas (Amancio 2011), assim como as primeiras tentativas de aproximação entre cinema e televisão, via EMBRAFILME, por meio do lançamento de "pilotos" para séries de televisão e, via TV Globo, por meio da realização do programa Globo Shell Especial. Frente ao contexto em relato, muitos intelectuais e artistas cinemanovistas migraram para emissoras de televisão, especialmente para a TV Globo.

Nesse período, a televisão foi consolidada no país, assentada, por sua vez, em uma organização industrial, com trânsito entre o público e o privado, diferentemente do cinema, com uma orientação mais artístico-cultural, dependente, cada vez mais, do apoio estatal. De emissora local, com a exibição de filmes estrangeiros e jornais, a TV Globo passou a ser uma rede nacional, com produção de teledramaturgia própria. Nessa nova posição, um padrão de qualidade técnico-estético e narrativo - o "padrão Globo de qualidade" - foi edificado e passou a nortear não apenas as produções da emissora, como, também, posteriormente, as próprias produções cinematográficas nacionais. Apesar das experiências estatais e empresariais, e do deslocamento de antigos revolucionários românticos para a televisão nos anos 1970, o divórcio estéticopolítico entre cinema e televisão perdurou, com a manutenção de negócios culturais e mercados paralelos.

Ao falar na crise e na Retomada do cinema nacional, requer ênfase o novo posicionamento adotado pelo Estado em relação ao cinema nacional. A extinção da EMBRAFILME, sem a substituição por outras estruturas, sublinhou a desobrigação do Estado com a cultura no início dos anos 1990 (Marson 2009). Para suprir a ausência de suporte estatal ao setor cinematográfico, foi instituída uma nova política de fomento, fundada em leis de incentivo (Lei Rouanet e Lei do Audiovisual). Apesar dos avanços trazidos, como o aumento de filmes nacionais lançados comercialmente, e a volta do público às salas de cinema, os mecanismos previstos nas leis tratavam apenas da produção cinematográfica, sem o aceno para uma articulação com os demais elos da cadeia produtiva e, por conseguinte, sem o aceno para uma atividade cinematográfica autossustentável (Bahia 2012). No final dos anos 1990, reivindicações do setor para uma reorientação das políticas públicas para o cinema convergiram para a edição da Medida Provisória 2.228-1/2001 e, correlativamente, para a instauração de um órgão institucional para o cinema: a Agência Nacional do Cinema (ANCINE). 
Caberia à agência fomentar e regular o conteúdo para cinema e para televisão; no entanto, de agência do audiovisual, a ANCINE foi reduzida à agência do cinema. Via política estatal, disputas, negociações, reivindicações e pressões adiaram a articulação entre cinema e televisão. ${ }^{3}$ Todavia, uma tentativa de articulação foi realizada via esfera privada, a partir de uma nova estratégia política e econômica empreendida pela Rede Globo, a saber, a criação de um departamento de cinema, a Globo Filmes. A emissora valeu-se, pois, de tal selo para, em prol da "defesa do conteúdo nacional", da ampliação e continuidade da sua legitimidade, e da antecipação de respostas às revisões da legislação audiovisual, atuar de forma direta sobre um produto em que já exercia significativa influência. A perspectiva industrialista seguida pela empresa, ancorada na comercialização intensa de filmes e no alto retorno de bilheterias do cinema brasileiro, concorreu para a promoção do "blockbuster nacional" (Butcher 2006). A criação da Globo Filmes demarcou uma nova relação entre cinema e televisão, conformando novas relações de poder, dependências, desigualdades e assimetrias.

\section{Leis de incentivo e políticas para o audiovisual}

Entre rupturas e continuidades, em consonância com vieses políticos, econômicos e culturais, a imbricação entre Estado e cinema, mediante regulações, incentivos e|ou subsídios, atravessou a historiografia do cinema brasileiro. $\mathrm{Na}$ era neoliberal, a nova postura adotada pelo Estado em relação à cinematografia apontava para a criação de mecanismos de incentivo, a instauração de um órgão institucional para o cinema, assim como a tentativa de regulação televisiva e de integração entre cinema e televisão. No âmbito da esfera privada, a nova postura adotada pela Rede Globo aludia à criação de um departamento de cinema, a Globo Filmes.

A partir da Medida Provisória 151, de 15 de março de 1990, decretada pelo Presidente Fernando Collor de Mello, a dissolução de

\footnotetext{
${ }^{3}$ Em 2002, em consonância com a Declaração do Canecão, documento elaborado por Nelson Pereira dos Santos e Orlando Senna, intelectuais e artistas apresentaram ao Presidente Luís Inácio Lula da Silva as principais reinvindicações para o setor audiovisual. Acompanhando essas diretrizes, ao assumir a Secretaria do Audiovisual (SAv), por indicação do Ministro Gilberto Gil, o cineasta Orlando Senna propôs uma reorganização do órgão e uma ampliação das suas atividades. Uma das propostas do Governo foi o resgate da ideia concebida inicialmente pelo Grupo Executivo de Desenvolvimento da Indústria do Cinema (GEDIC) quanto à ANCINE, qual seja, a regulação, fiscalização e elaboração de políticas de fomento não apenas para o cinema, mas para a atividade audiovisual como um todo, inclusa a televisão e outras plataformas digitais. Para tanto, foi proposta a criação de uma nova instituição, a Agência Nacional do Cinema e do Audiovisual (ANCINAV). Entretanto, diante da resistência das grandes empresas televisivas do país e de outros nichos do mercado, aliada à decisão do governo de não os confrontar, o anteprojeto da ANCINAV foi arquivado.
} 
órgãos federais voltados para o cinema, como a EMBRAFILME, o Conselho Nacional de Cinema (CONCINE), e a Fundação do Cinema Brasileiro (FCB), sem a substituição por outras estruturas, convergiu para a ausência de suporte estatal ao setor cinematográfico no país e, correlativamente, para a queda da produção de filmes. Apesar da duração de apenas dois anos, "a gestão de Collor deixou um legado extremamente negativo para o cinema nacional” (Leite 2005, 119). Falta de financiamentos; perda de mecanismos de proteção perante o cinema estrangeiro; término da cota de tela; abertura irrestrita de importações; rompimento de contratos; paralisação de produções; entre outros fatores, balizavam, em um contexto específico, os contornos da crise da atividade cinematográfica e, em um contexto mais amplo, a desobrigação do Estado com a cultura no início dos anos 1990 (Marson 2009).

Corroborando com o descaso do Governo com a cultura, nesse período, o Ministério da Cultura (MinC) foi rebaixado à condição de Secretaria. Com Ipojuca Pontes à frente da nova Secretaria, e com a ideia de que os bens culturais deveriam ser submetidos à lógica comercial, a desobrigação do Estado em relação ao cinema foi amplamente defendida. Já com Sérgio Paulo Rouanet, houve uma tentativa de reconstrução da cultura brasileira, notadamente do cinema nacional. Diante de tal conjuntura, uma nova política de fomento, fundada em incentivos fiscais, assegurados tanto pela Lei 8.313, de 23 de dezembro de 1991 (Lei Rouanet), destinada às atividades culturais, quanto pela Lei 8.685, de 20 de julho de 1993 (Lei do Audiovisual), destinada especificamente às atividades audiovisuais, engendrou a gradual "retomada" da cinematografia nacional. Mediante a Lei Rouanet, foi instituído o Programa Nacional de Apoio à Cultura (PRONAC), constituído por três mecanismos: o Fundo Nacional de Cultura (FNC), o Incentivo Fiscal (Mecenato), e o Fundo de Investimento Cultural Artístico (FICART). Dentre os mecanismos, merece ênfase o incentivo fiscal, que possibilita a aplicação de parte do Imposto de Renda em projetos culturais, seja por pessoas físicas, seja por pessoas jurídicas. Outro benefício, além da isenção fiscal sobre o valor do incentivo, foi a promoção da imagem institucional, em termos outros, a divulgação da marca da empresa. Caso aprovadas as propostas apresentadas ao MinC, aos proponentes caberia a captação de recursos junto a pessoas físicas ou jurídicas.

No tocante à Lei do Audiovisual, dois mecanismos merecem menção. O primeiro deles, prescrito no Artigo $1^{\circ}$, voltado para a aquisição de Certificados de Investimentos Audiovisuais por pessoas físicas ou jurídicas, relativos aos direitos de comercialização de obra cinematográfica brasileira de produção independente ou de projetos de exibição, distribuição e infraestrutura técnica na área audiovisual, descontados os recursos da compra dos certificados no imposto sobre a renda até o limite de $3 \%$ do imposto devido. Para a 
viabilização de uma obra cinematográfica mediante esse mecanismo, o projeto deveria ser submetido ao MinC e, caso aprovado, encaminhado para a Comissão de Valores Mobiliários (CVM) para a emissão do certificado. Já o segundo, prescrito no Artigo $3^{\circ}$, facultava às empresas distribuidoras de obras audiovisuais estrangeiras para comercialização no Brasil a utilização de $70 \%$ do imposto de renda pago, quando da remessa de rendimentos da exploração da obra para o exterior, na coprodução de filmes brasileiros.

Esse modelo, ulteriormente modificado pela Lei 9.323, de 5 de dezembro de 1996, foi adotado pela gestão cultural dos mandatos de Fernando Henrique Cardoso (1995-2002). A partir de 1993, com a ascensão de Itamar Franco à presidência, e com a recriação do MinC, houve uma reaproximação entre Estado e cinema. Mais uma vez, uma rearticulação política junto ao Estado foi buscada para a construção de um novo projeto para o cinema. A edição das leis de incentivo, e os valores investidos por meio dessas leis, das dotações oriundas do MinC e de outros organismos federais, como o Banco Nacional de Desenvolvimento Econômico Social (BNDES), Banco do Brasil (BB), Caixa Econômica Federal (CEF), foram algumas formas de apoio governamental. Outros aportes de recursos provinham de empresas públicas, como a Petrobrás, que, através da BR Distribuidora, investiu significativamente na atividade cinematográfica brasileira. Apesar de todos os estímulos à produção fílmica, as leis de incentivo subsidiaram praticamente a totalidade das produções do período, revelando a centralidade do instrumento na viabilização econômica do cinema, e realçando a dependência do setor cinematográfico em relação ao Estado. Entre os anos 1994 e 1999, por intermédio das leis de incentivo, foram investidos cerca US\$ 332 milhões na atividade cinematográfica, e foram produzidos 116 filmes de longa-metragem, 80 documentários, e um grande número de filmes de curta-metragem (Gatti 2007).

O advento dessas legislações e de outras disposições forjou o início de uma nova política cinematográfica. Entre as disposições, cabe a referência das definiçõoes de cota de tela, de filme nacional e de coproduções internacionais, estabelecidas pela Lei 8.401, de 8 de janeiro de 1992, regulamentada pelo Decreto 567, de 11 de junho de 1992; da liberação de recursos da EMBRAFILME via FICART, bem como da instituição da Comissão de Cinema para a seleção de filmes para financiamento, ambos nos termos do Decreto 575, de 23 de junho de 1992; da disponibilização desses recursos através do Prêmio Resgate do Cinema Brasileiro; da criação da Secretaria para o Desenvolvimento do Audiovisual (SAv), vinculada ao MinC; e outras (Marson 2009). Algumas disposições alternativas também podem ser mencionadas: no Rio de Janeiro, a criação da Riofilme Distribuidora de Filmes S/A, instituída pela Lei 1.672, de 25 de janeiro de 1991, importante distribuidora no cenário nacional, 
vinculada à Secretaria Municipal de Cultura, Turismos e Esportes, e, em São Paulo, a criação do Programa de Integração Cinema e Televisão (PIC-TV), com a produção e a exibição de filmes no circuito comercial e na TV Cultura.

É possível inferir que, a partir de meados dos anos 1990, durante o governo de Fernando Henrique Cardoso, o Estado retomou o "sentido da importância social, política e econômica da produção cinematográfica” (Fornazari 2006, 650). Para além disso, com o aumento de filmes nacionais lançados comercialmente, e a volta do público às salas de cinema, como mostram os dados dos gráficos que seguem abaixo; assim como com o emprego de técnicas, linguagens e estéticas advindas da televisão, e a elevação da qualidade das produções, não apenas o Estado, mas também a mídia, a sociedade e o próprio campo cinematográfico conferiram prestígio, visibilidade e legitimidade ao cinema nacional. (Bahia 2012). Dada a possibilidade de inserção dessa atividade em uma economia globalizada, e considerados os incentivos asseverados pelo Estado, o investimento em cinema nacional passou a ser percebido como "um negócio - e um bom negócio”, e outros campos do audiovisual, como as produtoras $\mathrm{O} 2$ Filmes e Globo Filmes, direcionaram o olhar para esse setor (Marson 2009, 58).

Apesar desses avanços, não houve a consolidação de um mercado de cinema brasileiro desvinculado do suporte estatal (Bahia 2012). Os mecanismos previstos nas leis de incentivo voltavam-se para a produção cinematográfica, sem o aceno para uma articulação com os demais elos da cadeia produtiva - distribuição/ comercialização, exibição, e infraestrutura de serviços - e, por conseguinte, sem o aceno para uma atividade cinematográfica autossustentável. Da mesma forma, não obstante a aproximação entre o cinema e a televisão, nos moldes acima mencionados, não houve uma vinculação comercial entre esses meios para a composição de um mercado audiovisual ou, em palavras outras, não foi urdida uma política multimídia (Canclini 2001). Ainda, por meio da política de incentivos, foi concedida à iniciativa privada não apenas a dedução do Imposto de Renda dos valores investidos em projetos culturais, mas também o poder de deliberação sobre os projetos exequíveis, o que conduziu a uma "administração privada de recursos públicos" (Butcher 2005, 19) e a um deslocamento da "gerência da cultura para a iniciativa privada" (Bahia 2012, 61).

No final dos anos 1990, esses e outros fatores, como, por exemplo, denúncias de irregularidades no uso desses mecanismos, fundamentaram as reivindicações do setor cinematográfico para fins de reorganização do mercado e reorientação das políticas públicas para o cinema. Frente a esse contexto, ocorreu o III Congresso Brasileiro de Cinema (CBC), realizado em junho de 2000, em Porto Alegre - RS. Com a presença de entidades e representantes de distintos segmentos do setor, esse evento, organizado pela Fundação 
Cinema RS (FUNDACINE), e presidido pelo cineasta Gustavo Dahl, demarcou a busca pela reestruturação e repolitização do cinema brasileiro.

Depreende-se do Relatório Final do CBC que, para o setor cinematográfico, cinema era um "problema de governo", como se vê neste excerto do documento: "Todos esses problemas se devem, em grande parte, à deficiente forma de relacionamento do setor cinematográfico com o governo e também à fragilidade do atual órgão governamental responsável”. A partir desse Congresso, com fulcro no entrelaçamento entre cultura, política e economia, o Estado reconheceu a necessidade de um novo delineamento para a relação Estado/cinema, e elegeu a integração entre os meios audiovisuais, sobretudo entre o cinema e a televisão, como um eixo estratégico para a consolidação de uma indústria audiovisual autossustentável e, nesse rumo, contou com a aquiescência do próprio campo cinematográfico, apesar da cisão de longa data entre um setor marcado pela autonomia cultural e artística e outro pela pretensão industrial e comercial (Ortiz Ramos 2004).

Para tanto, foi criado o Grupo Executivo para o Desenvolvimento da Indústria Cinematográfica (GEDIC), que, ao mesclar orientações culturais e econômicas, elencou cinco propostas para a inserção do cinema em um mercado global, a saber: a criação de um órgão institucional para a atividade cinematográfica; a redefinição das funções da SAv; a criação de um fundo de fomento para o desenvolvimento da cadeia produtiva; a reformulação das legislações existentes; e a disposição de uma legislação para a regulação do sistema televisivo. Dessas propostas, de acordo com a tentativa de alçar o cinema nacional a outro patamar de desenvolvimento, emergiu a Medida Provisória 2.228-1, de 6 de setembro de 2001, com adendos da Lei 10.454, de 13 de maio de 2002. A aludida medida, além de criar a Agência Nacional do Cinema (ANCINE), contemplou as diretrizes para a Política Nacional do Cinema (PNC); definiu a obra audiovisual brasileira; criou o Conselho Superior do Cinema (CSC); e versou sobre alguns mecanismos fiscais. ${ }^{4}$

A publicação dessa medida foi uma tentativa de rearticulação das ações governamentais e, a partir dela, uma nova institucionalidade foi concebida para o cinema brasileiro, ancorada na complementaridade de três órgãos estatais: o CSC, voltado à formulação da política nacional do cinema; a ANCINE, voltada ao

\footnotetext{
${ }^{4}$ Contribuição para o Desenvolvimento da Indústria Cinematográfica Nacional (CONDECINE); Fundos de Financiamento da Indústria Cinematográfica Nacional (FUNCINES); Programa de Apoio ao Desenvolvimento do Cinema Nacional (PRODECINE); e conversão da dívida externa em projetos de produção, distribuição, exibição e divulgação de obras audiovisuais brasileiras, de acordo com o inciso V, do Artigo $1^{\circ}$, da Lei 10.179, de 6 de fevereiro de 2001.
} 
fomento, regulação e fiscalização da indústria cinematográfica; e a SAv, voltada à assessoria, elaboração e execução de políticas, planos e diretrizes. A complementaridade entre esses órgãos fundar-se-ia nas distintas vinculações de cada um deles: o CSC, enquanto órgão superior e, portanto, de instância supraministerial, ficaria sob a égide da Casa Civil, ligada diretamente à Presidência da República; a ANCINE, por tratar de aspectos do "cinema industrial", ficaria sob a égide do Ministério do Desenvolvimento, Indústria e Comércio Exterior (MDIC); e a SAv, por tratar de aspectos do "cinema cultural", ficaria sob a égide do MinC. Paulatinamente, com o governo de Luiz Inácio Lula da Silva, houve um rompimento desse tripé institucional e, atualmente, os três órgãos estão vinculados ao MinC (Ikeda 2012). Esses novos parâmetros levaram a um significativo aumento de filmes nacionais lançados comercialmente: de 20 a 30 filmes anuais lançados até 2003, a produção foi elevada para mais de 40 filmes nos anos seguintes.

Apesar do alcance de público e de filmes lançados, e embora atendidas diversas requisições do campo cinematográfico, a regulação televisiva e a integração entre cinema e televisão não foram abarcadas pela legislação. Ainda que existisse um dispositivo na Medida Provisória 2.228-1/01, mais especificamente o Artigo 39, dedicado à programação internacional, e referente à opção de aplicação do valor correspondente a $3 \%$ do pagamento da Contribuição para o Desenvolvimento da Indústria Cinematográfica Nacional (CONDECINE) em produção nacional para cinema e televisão, tratava-se de um dispositivo isolado, não remetia à integração em questão. A regulamentação da obrigatoriedade de veiculação de $30 \%$ da produção audiovisual nacional na grade de programação dos canais abertos de televisão foi uma das reivindicações constantes nas resoluções finais do CBC. Essa requisição era extensiva à produção regional e estava amparada constitucionalmente no Artigo 221.

Art. 221 - A produção e a programação das emissoras de rádio e televisão atenderão aos seguintes princípios:

$[\ldots]$

II - promoção da cultura nacional e regional e estímulo à produção independente que objetive sua divulgação;

III - regionalização da produção cultural, artística e jornalística, conforme percentuais estabelecidos em lei. ${ }^{5}$

A relação entre esses meios, ainda em estágio primário, era almejada muito mais pelo setor cinematográfico do que pelo setor televisivo, e, nesse momento, o referido artigo não foi

\footnotetext{
${ }^{5}$ Disponível em http://www.planalto.gov.br/ccivil_03/constituicao/ConstituicaoCompilado.htm. Acesso em junho de 2018.
} 
regulamentado, reflexo da influência da Associação Brasileira de Rádio e Televisão (ABERT), para não afetar a verticalização da televisão e abrir espaço para a produção audiovisual independente, reduzindo, assim, o poderio econômico e cultural exercido pelo meio em tela. No mesmo rumo, não foi estabelecida uma quota de tela para filmes brasileiros na televisão. Os segmentos do setor cinematográfico também reivindicavam a participação na elaboração da Proposta de Emenda Constitucional (PEC), que visava a alteração do Artigo $222,{ }^{6}$ da Constituição Federal, para participação de capital estrangeiro nas emissoras de televisão, a fim de tratar da inclusão da produção audiovisual independente brasileira na programação das emissoras.

Outra resolução era relativa à regulamentação da TV por assinatura. Em 2000, na América Latina, mais de 85 milhões de domicílios eram equipados com aparelhos de televisão, e, nesses domicílios, havia 16 milhões de assinantes de pacotes de TV por Assinatura. Nesse mercado, o Brasil apresentava o maior índice de domicílios equipados com aparelhos de televisão, que correspondia a 37 milhões de domicílios, e no mercado mundial ocupava a $6^{\mathrm{a}}$ posição. No entanto, o país apresentava um dos menores índices de domicílios assinantes de TV, revelando a possibilidade de expansão desse mercado (Gatti, 2007, 115).

Quanto à produção audiovisual independente, sobretudo fílmica, havia pouca participação até ao ano de 2000. Na TV por Assinatura, essa participação não passava de 2\%; já na TV Aberta, cerca de 240 filmes eram exibidos mensalmente, dos quais 96,6\% eram estrangeiros e apenas 3,3\% eram brasileiros (Gatti 2007, 115). Nesses termos, caberia à ANCINE fomentar e regular não somente o conteúdo para cinema, mas também o conteúdo para televisão. Entretanto, os itens televisivos foram excluídos do texto final da Medida. De agência do audiovisual, a ANCINE foi reduzida a agência do cinema. Via política estatal, disputas, negociações, reivindicações e pressões que circunscreviam esses meios, foi adiado o trânsito do cinema pela cultura da mídia (Kellner 2001). Via política privada, essa articulação foi realizada com a criação do departamento de cinema da Rede Globo, a Globo Filmes. Entretanto, ausências e lacunas da política estatal não restaram preenchidas com tal empreendimento.

\footnotetext{
${ }^{6}$ Art. 222 - "A propriedade de empresa jornalística e de radiodifusão sonora e de sons e imagens é privativa de brasileiros natos ou naturalizados há mais de dez anos, ou de pessoas jurídicas constituídas sob as leis brasileiras e que tenham sede no País." Disponível em http://www.planalto.gov.br/ccivil_03/constituicao/Constituicao Compilado.htm Acesso em junho de 2018.
} 


\section{A Globo Filmes e a nova marca de fazer cinema}

Diferentemente das produções cinematográficas dos ciclos anteriores, que seguiam o referencial fílmico estrangeiro, a maioria dos filmes brasileiros produzidos a partir dos anos 1990 seguiu o referencial televisivo brasileiro, mais especificamente, o "padrão Globo". Capitalismo selvagem (1994), de André Klotzel; Carlota Joaquina, a Princesa do Brazil (1995), de Carla Camurati; ou O Quatrilho (1995), de Fábio Barreto foram alguns filmes produzidos nesse registro. A partir de meados dos anos 1990, uma conjunção de fatores direcionou a atenção da Rede Globo para o cinema. Um desses fatores estava diretamente relacionado com a perda da sua hegemonia frente à concorrência de programas veiculados por outras emissoras de televisão ${ }^{7}$ e a respectiva diminuição da audiência em alguns horários. Outro fator relacionava-se com as transformações das tecnologias de informação e comunicação (TIC), como a TV paga, os celulares, a Internet, a TV digital, e o correlato aumento da demanda por conteúdo audiovisual por meio das novas possibilidades de produção e difusão da informação, restando abalado o locus tradicional da televisão. Ademais, a Rede Globo atravessava grande crise, decorrente do endividamento da Globopar, holding dessa organização, em função de investimentos em TV a cabo (Net Serviços), TV por satélite (Sky) e na Globosat. Já o cinema brasileiro ingressava em um novo período, marcado pelo bom desempenho da produção fílmica, consoante os investimentos via leis de incentivos fiscais (Lei Rouanet e Lei do Audiovisual).

$\mathrm{O}$ surgimento da televisão impôs reconfigurações às cinematografias mundiais; no caso da cinematografia nacional brasileira, a centralização da produção televisiva em apenas um grupo de mídia, tanto no espaço narrativo (ficção) como no espaço informativo (jornalismo), conferiu alguns traços particulares ao cinema, observáveis através de "adesões ou reações à nova hegemonia formada no campo audiovisual brasileiro, o "padrão Globo de qualidade"” (Butcher 2006, 65). "Não se trata da televisão, simplesmente, mas da constituição de uma rede nacional e da transformação de um canal específico (a TV Globo) em potência audiovisual mundial, que empreendeu uma transformação profunda e redefiniu a imagem hegemônica do Brasil" (Butcher 2006). Ressalvadas algumas medidas adotadas pelo Poder Legislativo, como a obrigatoriedade da indicação do horário e da faixa etária recomendáveis para a exibição de programas, a interferência na exibição dos conteúdos sempre foi ínfima, restando às "entidades formadas pelos próprios representantes das emissoras de rádio e televisão a autocensura e a mediação da vigilância recíproca entre as

\footnotetext{
${ }^{7}$ Programas como a novela Pantanal, veiculada pela TV Manchete; o jornal Aqui Agora; e o programa Domingo Legal, ambos veiculados pelo Sistema Brasileiro de Televisão (SBT); e outros programas similares.
} 
empresas de comunicação" (Fechine 2008, 21). Para se distinguir de outras emissoras de televisão consolidadas com a apresentação de programas de cunho "popularesco", a Rede Globo apropriou-se do discurso da qualidade. Todo o esforço da emissora foi direcionado para a construção e difusão do "padrão Globo de qualidade".

Associado, inicialmente, à excelência técnica na difusão da sua programação (recepção fácil de sinal, abrangência da cobertura, boa definição de imagem, etc.), ao seu êxito empresarial (melhor infraestrutura, equipamentos de última geração, maiores salários e índices de audiência) e ao seu profissionalismo técnico-estético (programação visual arrojada, cenários e figurinos hollywoodianos, uso de efeitos especiais, investimento numa teledramaturgia nacional apoiada em um elenco com grandes nomes, etc.). Todo o investimento que culminou no chamado "padrão Globo de qualidade" foi favorecido pela fidelidade da emissora aos governos militares, recompensada não apenas com as verbas das propagandas oficias, mas também com pesados investimentos na infra-estrutura necessária à expansão da televisão para todo o território brasileiro. (Fechine 2008, 21)

Valendo-se de tal selo, a emissora passou a atuar de forma direta sobre um produto em que já exercia significativa influência, assim como passou a contar com a "capacidade de organização política do cinema brasileiro em seu favor, desmobilizando a indiferença e/ou oposição que, no passado, marcaram as posições do setor em relação à televisão" (Butcher 2006, 15). Nesse aspecto, uma nova estratégia política e econômica foi empreendida pela Rede Globo, a saber, a criação de um departamento de cinema, a Globo Filmes.

Em um contexto de transformações, de afirmação cultural frente às possíveis ameaças da globalização, a criação da Globo Filmes foi fundada em "defesa do conteúdo nacional". Desde os anos 1930, os meios de comunicação já exerciam importante papel na integração e formação de mercados nacionais, urdidos em resposta às "necessidades e exigências do mercado internacional" (MartinBarbero 2003). Tal influência se estendeu aos modos de regulação dos meios de comunicação brasileiros, nos quais a defesa do nacionalismo e a defesa de interesses específicos imiscuíram-se. Ao assentir a propriedade de empresas jornalísticas e de radiodifusão apenas por pessoas físicas e brasileiras, a legislação nacional contribuiu para a preeminência de um pequeno grupo de pessoas físicas, especialmente empresas familiares, à frente da televisão.

Além de respaldada por diversas Constituições, tal postura foi reafirmada pelo Código Brasileiro de Telecomunicações. Para além disso, diferentemente do cinema, a televisão recebeu altos investimentos estatais em infraestrutura, quer mediante o Sistema Nacional de Telecomunicações, que levou o sinal televisivo aos lugares mais remotos do país, quer através do estímulo ao crédito para a aquisição de aparelhos de televisão. Considerando que se trata 
da exploração privada de uma concessão pública, por intermédio do sistema de afiliação, a Rede Globo desviou-se das imposições legais relativas ao número de concessões por pessoa no território nacional, formando um espaço público de "integração nacional" e edificando um oligopólio presente em todo o país.

A hegemonia da Rede Globo foi construída a partir de um discurso ancorado em dois pilares: um deles relativo à competência empresarial, isto é, à "capacidade de se firmar em um mercado de livre concorrência”; o outro relativo ao nacionalismo, à "função social da emissora na construção e na solidificação da identidade nacional, contra a penetração da cultura estrangeira" (Butcher 2006, 39). Discurso similar conferiu legitimidade à instauração da Globo Filmes, qual seja, a competência: "a Globo Filmes teria sido criada com a função de 'ensinar' o cinema brasileiro a se superar nos aspectos em que ele foi incompetente, ou seja, em uma capacidade de compreender efetivamente o gosto do público e criar uma base comercial capaz de gerar a sua própria sustentabilidade", e o nacionalismo: "a Globo Filmes teria entrado em campo como mais um elemento da emissora em defesa da identidade nacional" (Butcher 2006, 53).

Sob o discurso do nacionalismo, a Rede Globo assegurou a reprodução do eixo vertical de um poderio econômico, político e cultural já estabelecido. Ao lançar-se à frente da produção audiovisual brasileira, em nome da insurreição ao imperialismo cultural, a emissora reivindicou para si o status de produtora da identidade nacional, exercendo opressão e repressão das diferenças. Tanto na programação quanto no sítio eletrônico da emissora, bem como no sítio da Globo Filmes, os apelos identitários são recorrentes.

Na programação da emissora, o apelo é direto: "Globo, a gente se vê por aqui”. No site institucional, o texto que apresenta a história da TV Globo ratifica essa preocupação por meio de declarações como "Brasil: A principal atração da programação da Globo", "A Globo vê o Brasil. O Brasil se vê na Globo", "A dramaturgia da Globo reflete os costumes, os hábitos e a cultura nacional" (referindo-se às suas telenovelas e minisséries) ou "Um país ligado na mesma emoção" (ao apresentar seu jornalismo esportivo). (Fechine 2008, 23)

Globo Filmes, o cinema que fala a nossa língua. [...] Com a missão de contribuir para o fortalecimento da indústria audiovisual nacional, apostando em obras de qualidade e valorizando a cultura brasileira, participou dos maiores sucessos de bilheteria da retomada. [...] A Globo Filmes também tem por objetivo promover a sinergia entre o cinema e a televisão, sempre atenta ao reconhecido padrão Globo de qualidade. Suas atividades se baseiam nas parcerias com produtores independentes e distribuidores 
nacionais e internacionais, em uma associação de excelência para levar ao público o que há de melhor no cinema brasileiro. ${ }^{8}$

Vale sublinhar que o excerto acima corresponde às informações trazidas no sítio eletrônico da Globo Filmes em 2014. Nos tempos contemporâneos, o slogan segue o mesmo: "Globo Filmes, o cinema que fala a nossa língua” e, para corroborá-lo, são apresentados diversos depoimentos tanto de produtores quanto de diretores que já fizeram parceria de trabalho com a empresa e que, portanto, podem reiterar a sua importância no mercado audiovisual nacional. Nesse sentido, são dignos de destaque alguns desses olhares: "O cinema brasileiro é a expressão da cultura brasileira" (Produtora Vilma Lustosa); "É bacana a Globo Filmes estar dando a chance de a gente abrir o leque, estar querendo falar de assuntos que afetem a nossa cultura, que falem um pouco do nosso país"; "Hoje em dia, eu não consigo mais ver um cinema que só cumpre a função dele de filme na tela, eu acho importantíssimo o cinema chegar na televisão também" (Diretor Breno Silveira); "São coprodutores, não são pessoas que estão comprando o seu filme" (Diretor René Sampaio); "A Globo Filmes é legitimamente uma coprodutora pelo papel que ela tem no acompanhamento artístico do projeto e nas decisões desse projeto"; "Não cabe a esse superior uma visão autoritária do processo, mas uma visão colaborativa"; "Ela procura fornecer também inteligência, experiência, visão de mercado, visão de marketing, e isso na época do lançamento é muito importante" (Produtora Mariza Leão); "Ela contribui e muito com o fortalecimento de apresentação do projeto no mercado" (Produtor Augusto Casé); "Um dos aspectos mais positivos que a gente vê na relação com a Globo Filmes é exatamente a sinergia que a gente consegue criar do ponto de vista artístico também"; "Poder contar com a Globo divulgando o filme com todas as ações que a gente faz de cross media dentro da programação da Globo"; "É realmente muito gratificante quando a gente vê o filme sendo exibido na própria TV Globo"; "Vendem os seus produtos para o mundo inteiro, e estão colocando, também, esse sistema a serviço dos filmes" (Produtor Fabiano Gullane); "Uma delícia ver lá o teu filme no meio do Jornal Nacional ou da novela das 8 , esse é um fator também muito determinante para o sucesso do seu filme, e isso é um benefício muito importante dessa coprodução" (Produtora Iafa Britz); "Um bom filme precisa de um bom lançamento, e um bom lançamento vem dessa cooperação, desse trabalho bem feito entre a distribuidora e a Globo Filmes" (Diretor Roberto Santucci); "Cada vez mais a Globo Filmes se atenta para os filmes que não são eminentemente comerciais" (Produtora Vânia Catani); “Apoiando projetos documentais significa também estar com um pé em valores que vão

8 Disponível em http://globofilmes.globo.com/quemsomos.htm. Acesso em janeiro de 2014. 
além talvez de projetos que são só comerciais, que também são muito importantes" (Diretor Victor Lopes). ${ }^{9}$

Considerando o importante papel exercido pela cultura na conformação das identidades nacionais, merecem atenção os diferentes vieses teóricos e ideários que podem orientá-la, "indo desde o reconhecimento da importância desses construtos identitários para um povo ou nação até, em registro totalmente contraposto, o desvelamento da construção do nacional como mera ideologia que pretende esconder interesses particulares de setores minoritários da população" (Rubim 2004, 25). Nesse sentido, Antonio Albino Canelas Rubim, no texto Televisão e Políticas Culturais no Brasil (2004), faz referência às análises sobre identidade tecidas por Benedict Anderson, através da noção de comunidades nacionais imaginadas. Alude o autor que, no contexto brasileiro, nem a literatura nem o cinema tiveram a mesma influência que a televisão em termos de identidade. ${ }^{10} \mathrm{O}$ apelo nacionalista em comento, que serviu não apenas para o projeto de integração nacional dos governos militares, mas também como estratégia de defesa de mercado da Rede Globo contra os produtos norte-americanos, foi apontado por Ridenti como uma "herança caricatural" da preocupação com o nacional-popular dos artistas e intelectuais de esquerda dos anos 1960.

A adoção dessa "brasilidade" pela televisão, que antes defendia políticas emancipatórias, foi decorrente, em parte, da própria inserção de alguns desses artistas e intelectuais na emissora. Frente às pressões pela democratização das mídias, a Rede Globo incorporou explicitamente o discurso nacionalista autopromocional. A "redescoberta do povo brasileiro" ou a busca da identidade nacional, distante do discurso dos anos 1960, apresentava-se mais como uma preocupação em abrir espaço para a diversidade regional e para o pluralismo sociocultural na programação. Movida por um novo posicionamento mercadológico, determinado por uma preocupação maior com a concorrência e por um momento político em que uma maior legitimação perante os segmentos organizados da sociedade era necessária, o "padrão de qualidade" foi redefinido, mediante um esforço para "associar sua 'qualidade' não apenas à produção de conteúdos nacionais, mas também à responsabilidade social e à isenção política da programação, assim como ao estímulo a inovações estéticas e proposição de novos formatos" (Fechine 2008, 23).

\footnotetext{
${ }^{9}$ Disponível em http://globofilmes.globo.com/quem-somos/ Acesso em junho de 2018.

${ }^{10}$ Em Bye Bye Brasil, filme de Cacá Diegues, “a viagem da Caravana 'Holiday', com suas mambembes atrações, foge sempre das espinhas de peixe (antenas) da televisão, denunciando a invasão territorial e simbólica promovida pela televisão, que vai integrando o Brasil através de sua teia física e simbólica” (Rubim 2004, 26).
} 
Grande parte do cinema também resgatou o discurso do nacionalismo, mas com ideias distintas da brasilidade revolucionária dos meios intelectuais e artísticos já referidos. O discurso reapareceu de modo menos politizado e sob a nova égide da diversidade. Com enfoque em uma produção audiovisual dotada de qualidade técnicoestética e de apelo popular, Guel Arraes foi um dos protagonistas da experiência de integração entre cinema e televisão através da conversão de produtos feitos para a televisão, em filmes como $O$ Auto da Compadecida e A Invenção do Brasil. Embora os membros do Núcleo de Guel Arraes adotassem um posicionamento crítico em relação à realidade social brasileira, "já não pesava tanto sobre eles a pressão sentida pela geração anterior por um engajamento político ou comprometimento direto com o projeto de redemocratização do país" (Fechine 2008, 29), isso porque, quando começaram a ocupar espaços mais expressivos na cena intelectual-artística, a conjuntura brasileira já era menos opressora. No entanto, o desenvolvimento de uma estrutura de sentimento fundada em irreverência quanto à própria televisão conferiu a esse grupo a institucionalização de um núcleo dentro da Globo, estendendo-se tal influência, posteriormente, para além dos limites da emissora. O projeto éticoestético desse Núcleo era pautado, de um lado, pela "deliberação em reinterpretar a realidade social e a produção cultural do País a partir da perspectiva do não-oficial, do popular e do periférico" e, de outro, pela "clara ambição de fazer do seu experimentalismo formal uma 'marca' da Rede Globo e, ao mesmo tempo, uma estratégia de legitimação do próprio grupo dentro da emissora" (Fechine 2008, 49).

Para Maria Elisa Cevasco (2001), posturas culturais adotadas em determinados momentos podem ser vistas como respostas de comunidades historicamente situadas a mudanças não precisamente artísticas. No caso em menção, tratava-se de uma "ruptura autorizada" com paradigmas anteriores, ante a necessidade de inovação própria da lógica da indústria cultural. As produções do Núcleo eram regidas pelas lógicas do mercado brasileiro audiovisual, mais especificamente, pela lógica da Globo Filmes, que, conforme esclarece Pedro Butcher (2006), através da articulação entre produção cinematográfica e televisiva, acenava para a promoção do "blockbuster nacional". Ao mesmo tempo que a incorporação das "frações rebeldes" convergia para a manutenção da dominação televisiva, essa mesma incorporação convergia também para a aceitação das formas artísticas escolhidas pelo grupo. É possível falar em uma adequação das "postulações estéticas oriundas de outros campos e sua consequente contribuição, a partir dessa incorporação, para a consolidação de um estilo novo na televisão, e a novas práticas e processos de produção no cinema nacional" (Fechine 2008, 32).

No final de 1998, a Globo Filmes passou a atuar no cenário audiovisual, sob a direção de Daniel Filho (direção geral e artística), 
Tom Flórido (planejamento) e Marco Aurélio Marcondes (distribuição e comercialização). A atuação desse departamento contemplava a transformação dos grandes sucessos da emissora em produtos cinematográficos, como a conversão de minisséries em filmes de longa-metragem e a promoção de "filmes de qualidade" com potencial comercial, realizados por produtoras independentes. Desses modos de atuação, para fins de valer-se de incentivos fiscais, a associação com produtoras independentes foi o caminho possível para as realizações da Globo Filmes. ${ }^{11}$ A participação da empresa, na maioria dos casos, não envolvia financiamentos diretos nas produções filmográficas, mas sim um capital "virtual", consubstanciado em um espaço midiático fornecido pela emissora para divulgação nacional do projeto à época do lançamento, seja pela forma tradicional, por meio de anúncios e spots, seja por outras formas, sobretudo, cross media, por meio de referência e promoção em programas jornalísticos e ficcionais. A estrutura de grade de programação telenovela + jornal local + telenovela + jornal nacional + telenovela possibilitava "grande influência em determinadas camadas do imaginário coletivo ao estabelecer uma inter-relação entre jornalismo e telenovela, fato e fantasia" (Butcher 2006, 56) e, à vista disso, conferia eficácia ao recurso de cross media para o fomento das produções cinematográficas. ${ }^{12}$

A cross media é um exemplo de como a concentração da produção sob um mesmo teto permite uma cuidadosa manipulação do conteúdo de programas jornalísticos e ficcionais no sentido de se "produzir fatos" que possam interessar à emissora. Desde o começo da Globo Filmes, a cross media tem sido intensamente utilizada para promover os filmes co-produzidos pela empresa, e representam o diferencial mais importante, por exemplo, em relação às campanhas dos blockbusters americanos. Seu formato mais simples é a citação do filme por um personagem de novela identificado com a temática ou, ainda, uma reportagem em um programa jornalístico que apresente um tema afim ao do filme. (Butcher 2006, 80)

Com essa modalidade, a Globo Filmes poderia aderir a um projeto em qualquer fase, até mesmo a um projeto já concluído, como ocorreu com o filme Cidade de Deus (2002), dirigido por Fernando Meirelles, e produzido pela O2 Filmes. À época do lançamento do filme, entre outras formas de divulgação cross media concedidas pela TV Globo, uma série de reportagens sobre a violência nas favelas cariocas foi veiculada no Jornal Nacional. Por retratar o surgimento da Cidade de Deus, entre os anos 1960 e 1980, e levar violência para as telas do cinema, o filme obteve apoio apenas

\footnotetext{
11 Algumas associações da Globo Filmes foram realizadas com as seguintes produtoras: Diler \& Associados; Conspiração Filmes; Total Entertainment; Natasha Filmes; Lereby Filmes; Rio Vermelho Produções; O2 Filmes; LC Barreto; Vídeo Filmes; Criatura; Documenta Filmes; 3 Tabela Filmes; Media Bridge; entre outras. 12 Para a manutenção da hegemonia da Rede Globo, o referido modelo de programação segue vigente, aberto apenas para irrisórias alterações.
} 
depois de finalizado, mais precisamente, após exibido no Festival de Cannes. Contudo, o sucesso do filme, com mais de três milhões de espectadores, as indicações às premiações da Academy Awards, e o reconhecimento das críticas nacional e internacional fizeram a emissora repensar o êxito esperado apenas de filmes detentores da estética televisiva, especialmente infantis, históricos ou comédias. No entanto, a preferência da Globo Filmes recaía sobre projetos ainda na fase inicial, para sugestões, caso necessário, quanto ao roteiro, orçamento e elenco. A dimensão do apoio da emissora estava condicionada pela adesão às sugestões por ela apresentadas. Em um primeiro momento, de 1998 a 2002, a Globo Filmes trabalhou em dois a três filmes por ano. Simão, o fantasma trapalhão (1998), dirigido por Paulo Aragão, e distribuído pela Columbia Pictures, foi o primeiro filme a carregar o selo da Globo Filmes.

A estreia de Simão, o fantasma trapalhão, no dia $1^{\circ}$ de dezembro de 1998, seria apenas mais um lançamento de uma comédia de Renato Aragão, se não fosse por um pequeno detalhe: o filme marcou a entrada em cena da Globo Filmes, divisão da maior rede de TV aberta do país voltada para a co-produção de longa-metragens brasileiros. No contexto da "retomada", o surgimento da Globo Filmes transformou o panorama do mercado ao criar as condições necessárias para a emergência do novo "blockbuster" nacional. (Filme B 2008)

Zoando na TV (1999), dirigido por José Alvarenga Jr., distribuído igualmente pela Columbia Pictures, e com a apresentadora Angélica à frente, foi o primeiro filme concebido com recursos próprios da TV Globo. Já Orfeu (1999), dirigido por Carlos Diegues, e distribuído pela Warner, foi a primeira aposta de associação da Globo Filmes com um produtor externo. As primeiras produções com o selo da Globo Filmes levaram cerca de seis milhões de espectadores aos cinemas, revelando o alto índice de público em filmes com o selo da emissora. A aproximação entre cinema e televisão e o entrecruzamento de narrativas televisivas e cinematográficas levaram ao hibridismo das mídias.

O formato da minissérie O Auto da Compadecida (1999), de Guel Arraes, adaptada do romance homônimo de Ariano Suassuna, foi ajustado para ser exibido como longa-metragem nas telas do cinema. Não obstante a grande divulgação midiática, houve dúvida quanto à repercussão junto ao público de um filme decorrente de um programa disponibilizado como série na TV aberta. No entanto, o filme obteve alto índice de público, com mais de dois milhões de espectadores, asseverando a capacidade de inserção dos produtos da Globo Filmes no mercado de cinema. Cidade de Deus marcou um movimento inverso: o filme de longa-metragem foi transformado em uma minissérie - Cidade dos Homens. Tratava-se de um desdobramento do filme Cidade de Deus, com os mesmos criadores, equipe e elenco. Mas um projeto era o avesso do outro. De acordo com o depoimento de Fernando Meirelles, Cidade de Deus era "um 
drama com um toque de comédia sobre traficantes no Rio, a comunidade aparece apenas como pano de fundo"; Cidade dos Homens era "uma comédia, com um toque de drama sobre uma comunidade do Rio de Janeiro, os traficantes aparecem só como pano de fundo". ${ }^{13}$ Com alto índice de audiência, a minissérie garantiu a realização de outras temporadas, assim como um novo filme de longa-metragem sobre os personagens (Laranjinha e Acerola).

Entre os projetos recentes da TV Globo, três daqueles que tiveram maior repercussão com a crítica especializada foram produzidos por produtoras independentes, a O2 Filmes e a $\mathrm{HB}$ Filmes. Um deles foi a série Carandiru - Outras Histórias (2005), dirigida por Hector Babenco, e produzida pela HB Filmes, série baseada no filme que leva o mesmo nome (2003), dirigido pelo mesmo cineasta, recorde de bilheteria no cinema nacional; os outros dois foram produzidos pela O2 Filmes - a série Cidade dos Homens, e Antônia, minissérie exibida em duas temporadas, que surgiu do filme homônimo, dirigido por Tata Amaral. A proposta da minissérie foi apresentada à produtora, que, por meio do Núcleo Guel Arraes, foi realizada pela Rede Globo. Em resposta ao novo momento da produção audiovisual no Brasil, a emissora abriu espaço para um mercado que, apesar de incipiente, crescia rapidamente: a produção independente. O Núcleo de Guel Arraes foi a porta de entrada para muitas dessas produtoras na Rede Globo.

A atuação da Globo Filmes, voltada para produzir efeitos no momento do lançamento dos filmes, muitas vezes assegura a presença do público e a renda das bilheterias. Carandiru (2003), de Hector Babenco; Deus é Brasileiro (2003), de Carlos Diegues; Didi O Cupido Trapalhão (2003), de Paulo Aragão e Alexandre Boury; Lisbela e o prisioneiro (2003), de Guel Arraes; Maria, mãe do filho de Deus (2003), de Moacyr Góes; Xuxa e os duendes 2 (2002), de Paulo Sérgio Almeida e Rogério Gomes; foram alguns títulos coproduzidos pelo departamento.

Desde a criação até 2007, a Globo Filmes participou da produção de mais de 60 filmes nacionais, com um público estimado em 70 milhões. Em 2003, ano histórico para o mercado cinematográfico brasileiro, os filmes nacionais representavam quase $22 \%$ desse mercado, e o público de filme nacional correspondia a cerca de 22 milhões, um aumento de $202 \%$ em relação ao período anterior. Nesse ano, 47 filmes foram lançados, 12 deles coproduzidos pela Globo Filmes e responsáveis por $88 \%$ do total de ingressos vendidos. Em um contexto de crescimento do mercado cinematográfico, o ingresso da Globo Filmes nesse setor representou uma alta concentração de público e de renda dos filmes produzidos pela empresa. Os altos índices levaram ao aumento do apoio do

\footnotetext{
${ }^{13}$ Disponível no conteúdo extra do DVD Cidade dos homens (2002).
} 
departamento ao cinema nacional: em 2000, 2 filmes foram apoiados pela empresa; em 2007, esse número passou para 15.

Ao longo dos anos, a Rede Globo investiu pouco em produção nacional, com a inserção de apenas alguns filmes brasileiros na grade de programação. Ao final dos anos 1990, a criação da Globo Filmes demarcou uma nova relação entre cinema e televisão. Em prol da "defesa do conteúdo nacional", da ampliação e da manutenção de legitimidade da emissora, e da antecipação de respostas às revisões da legislação audiovisual desenhada a partir dos governos de Fernando Henrique Cardoso e de Luís Inácio Lula da Silva, a TV Globo passou a visar esse setor. ${ }^{14}$ Todavia, perante a resistência para exibição de filmes nacionais na própria emissora, não restou consolidado um espaço para o cinema na programação. A maioria dos filmes que logrou êxito comercial a partir dos anos 2000 foi coproduzido pela Globo filmes, configurando novas relações de poder, dependências, desigualdades, assimetrias. A visão industrialista adotada pela empresa, ancorada na comercialização intensa de filmes e no alto retorno de bilheterias do cinema brasileiro, possível pela posição da Rede Globo no cenário nacional, engendrou “outras formas de fazer cinema no Brasil” (Bahia 2012, 151). O cinema brasileiro, além de enfrentar a concorrência com o produto estrangeiro, também passou a enfrentar a concorrência com o produto televisivo, a partir do deslocamento do "padrão Globo de qualidade" para o cinema.

\section{Considerações finais}

Em um primeiro momento, dados os distintos códigos ético-estéticos adotados pelo cinema e pela televisão, a relação entre esses meios foi marcada pelo divórcio estético-político. Não obstante as tentativas de aproximação entre cinema e televisão, seja via estatal, através da EMBRAFILME, seja via empresarial, através da TV Globo, hierarquias e dicotomias perduraram: de um lado, a televisão, com traços de um negócio de teor empresarial-comercial, com trânsito entre o público e o privado; de outro, o cinema, de teor artísticocultural, dependente do apoio estatal. Nos anos finais de 1990, apesar da tentativa de articulação entre cinema e televisão, mediante instrumentos regulatórios e institucionais, o meio televisivo não restou contemplado pelo texto da Medida Provisória 2.228-1/2001, nem pelo âmbito de atuação da ANCINE. Já pela via privada, a criação da Globo Filmes, e o crescimento desse departamento de

\footnotetext{
14 Além da criação da Globo Filmes, outras iniciativas da Rede Globo foram a fundação do Canal Brasil, uma joint-venture entre a Globosat e o Grupo Consórcio Brasil (formado pelos produtores e cineastas Luiz Carlos Barreto, Zelito Viana, Marco Altberg, Aníbal Massaini e Roberto Faria), em1998; a instituição do projeto Brasil Total, com a atriz Regina Casé e o antropólogo Hermano Vianna à frente, em 2002; entre outras.
} 
filmes da TV Globo acenou para a articulação em comento e instaurou uma nova marca de fazer cinema.

\section{BIBLIOGRAFIA}

Amancio, Tunico. 2011. Artes e manhas da Embrafilme: cinema estatal brasileiro em sua época de ouro (1977-1981). $2^{a}$ edição. Niterói: EdUFF.

Bahia Lia. 2012. Discursos, políticas e ações: processo de industrialização do campo cinematográfico brasileiro. São Paulo: Rumos Itaú Cultural.

Bourdieu, Pierre. 1992. A economia das trocas simbólicas. São Paulo: Perspectiva.

Butcher, Pedro. 2006. "A dona da história: Origens da Globo Filmes e seu impacto no audiovisual brasileiro.” Dissertação de Mestrado. Rio de Janeiro.

-——. 2005. O cinema brasileiro hoje. São Paulo: Publifolha.

Canclini, Néstor Garcia. 2001. Consumidores e cidadãos. Rio de Janeiro: Editora UFRJ.

Cevasco, Maria Elisa. 2001. Para ler Raymond Williams. São Paulo: Paz e Terra.

Fechine, Yvana. 2008. "Núcleo Guel Arraes: formação, influências e contribuições para uma TV de qualidade." In Guel Arraes: um inventor do audiovisual brasileiro, organizado por Alexandre Figueroa e Yvana Fechine. Recife: CEPE.

Forzanari, Fabio Kobol. 2006. "Instituições do Estado e políticas de regulação e incentivo ao cinema no Brasil: o caso ANCINE e ANCINAV". Revista. Administração Pública, Rio de Janeiro, vol. 40, n. 4 (julho/agosto): 647-677.

Gatti, André Piero. 2007. Embrafilme e o cinema brasileiro. São Paulo: Centro Cultural São Paulo.

—_—. 2007. "O mercado cinematográfico brasileiro: uma situação global?" In Cinema no mundo: indústria, política e mercado na América Latina, organizado por Alessandra Meleiro. São Paulo: Escrituras.

Ikeda, Marcelo. 2012. Lei da ANCINE comentada (Medida Provisória 2.228-1/01). Rio de Janeiro: WSET Multimídia.

Kellner, Douglas. 2001. A cultura da mídia. Bauru: Edusc.

Leite, Sidney Ferreira. 2005. Cinema brasileiro: das origens à Retomada. São Paulo: Fundação Perseu Abramo. 
Marson, Melina Izar. 2009. Cinema e Políticas de Estado: da Embrafilme à ANCINE. São Paulo: Escrituras Editora.

Martín-Barbero, Jesús. 2003. Dos meios às mediações: comunicação, cultura e hegemonia. Rio de Janeiro: Editora UFRJ.

Mattelart, Armand. 2005. Diversidade cultural e mundialização. São Paulo: Parábola.

Miceli, Sérgio (org.). 1984. Estado e cultura no Brasil. São Paulo: Difel.

Ortiz, Renato. 1994. A moderna tradição brasileira. São Paulo: Brasiliense.

Ortiz Ramos, José Mário. 2004. Cinema, televisão e publicidade: Cultura popular de massa no Brasil nos anos 1970-1980. $2^{\mathrm{a}}$ ed. São Paulo: Annablume.

_-_. 1983. Cinema, estado e lutas culturais. Rio de Janeiro: Paz e Terra.

Ridenti, Marcelo. 2000. Em busca do povo brasileiro: artistas da revolução, do CPC à era da TV. Rio de Janeiro: Record.

Rubim, Antônio Albino Canelas e Lindinalva Silva Oliveira Rubim. 2004. "Televisão e políticas culturais no Brasil". Revista USP, São Paulo, nº. 61 (março/maio): 16-29. 